Tersedia online di: http://ejournal-balitbang.kkp.go.id/index.php/JP
e-mail:jurnalpari@gmail.com
JURNAL PARI
Volume 4 Nomor 2 Desember 2018
p-ISSN: 2502-0730
e-ISSN : 2549-0133

\title{
STUDI KELAYAKAN PENGEMBANGANSISTEM PERPUSTAKAAN DIGITAL BERBASIS WEB DI PERPUSTAKAAN SEKOLAH TINGGI PERIKANAN (STP) JURUSAN PENYULUHAN PERIKANAN (JURLUHKAN) BOGOR
}

\section{THE FEASIBILITY STUDIES ON WEB-BASED DIGITAL LIBRARY SYSTEM DEVELOPMENT IN LIBRARY OF SEKOLAH TINGGI PERIKANAN (STP) JURUSAN PENYULUHAN PERIKANAN (JURLUHKAN) BOGOR}

\author{
Dadan Syachrulramdhani \\ Sekolah Tinggi Perikanan Jurusan Penyuluhan Perikanan Bogor \\ Diterima tanggal : 12 September 2018 Diterima setelah perbaikan : 25 Oktober 2018 \\ disetujui terbit : 13 Desember 2018
}

\begin{abstract}
ABSTRAK
Kemajuan pesat TI harus mampu diimbangi, diantisipasi kemajuan perpustakaan penyedia informasi, penyimpan pengetahuan, strateginya mengembangkan perpustakaan digital berbasis web sehingga perlu dilakukan studi kelayakan pengembangan sistem perpustakaan digital berbasis web perpustakaan digital STP Jurluhkan Bogor. Pengembangan sistem perpustakaan perlu didukung elemen dasar; kondisi ideal SDM, koleksi,infrastruktur,SOP,manajemen,anggaran. Studi bertujuan menentukan, merekomendasikan kelayakan yang harus dimiliki. Pendekatan penelitian; menganalisis, membandingkan kondisi ideal elemen dasar dengan kondisi standar perpustakaan digital Pustaka Bogor dan kondisi objektif perpustakaan digital STP Jurluhkan Bogor, untuk mengetahui sejauh mana unsur-unsur dasar perpustakaan digital ideal dapat dipenuhi, menentukan kelayakannya dan merekomendasikan kondisi standar unsur-unsur dasar perpustakaan digital STP Jurluhkan Bogor. Prosedur yang dilakukan: studi literatur, menggambarkan kondisi ideal elemen dasar perpustakaan digital berdasarkan sumber data tempat: badan standardisasi ANTA dari CAUDIT,APJII PPAUME dari ITB,IEEE,NISO,IFLA, sumber data simbol: buku, sumber litertur offline dan online dan sumber data bentuk orang: pengelola perpustakaan. Desain penelitian, penelitian deskriptif studi kasus, tahapan desain penelitiannya: pembuatan instrumen wawancara, daftar kecocokan, pengumpulan data dan analisis data hasil wawancara dengan membandingkannya. Diperoleh hasil kondisi tingkat kelayakan elemen dasar perpustakaan digital perpustakaan STP Jurluhkan 50,00\% kondisi SDM, 21,40\% kondisi koleksi, $95,20 \%$ kondisi infrastruktur, 0,00\% kondisi SOP, 58,30\% dan 11,11\% kondisi anggaran, sehingga perpustakaan STP Jurluhkan Bogor belum layak 100\% untuk melakukan pengembangan perpustakaan digital berbasis web, sehingga perlu meningkatkan kelayakan elemen dasar perpustakaan digitalnya.
\end{abstract}

Kata kunci: Studi kelayakan; perpustakaan digital; web; Sekolah Tinggi Perikanan.

\begin{abstract}
The rapid advancement of IT must be accompanied by the rapid progress of the library as a provider of information and knowledge repository. The library is required to provide sources of information in digital form. Development of digital libraries should be supported by the ideal conditions for the basic elements, namely: human resources, collections, infrastructure, SOP, management and budget. The initial step is to match the actual condition with the ideal conditions of the basic elements of digital libraries based on the sources of information from institutions which issued standards such as CAUDIT (2001), APJII and PPAUME (2000), IEEE (2009), NISO (2007) and IFLA (2009). The next step was doing feasibility analysis of the basic elements of digital
\end{abstract}


libraries in the Library of STP Jurluhkan Bogor. The study aimed to determine the level of feasibility of the basic elements of digital libraries and recommended the feasibility of the basic elements that must be met. The study used a descriptive research design case study (case study) to conduct a feasibility study. Data were collected using interviews method with interview instruments and checklist. The results obtained by the conditions of the feasibility of the basic elements of digital libraries in library of STP jurluhkan Bogor are $50.00 \%$ human, $21.40 \%$ collection, $95.20 \%$ infrastructure, $0.00 \%$ SOP, 58.3\% management, and 33.33\% state budget. Based on the condition of the basic elements feasibility of library of STP Jurluhkan Bogor, it has not been feasible to conduct web-based digital library development, so there is the need to increase its level of eligibility in order to develop the basic elements of digital libraries.

Keywords: feasibility studies; digital libraries; web; College of Fisheries.

\section{PENDAHULUAN}

Pesatnya kemajuan TI harus mampu diimbangi bahkan diantisipasi oleh perpustakaan sebagai salah satu information provider and knowledge repository (Rufaidah, 2007). Salah satu strateginya dengan mengembangkan perpustakaan digital berbasis web. Untuk itu perlu dilakukan studi kelayakan (feasibility study), pengembangan sistem perpustakaan digital berbasis web di Perpustakaan STP Jurluhkan Bogor.

Pengembangan perpustakaan digital berbasis web perlu didukung oleh elemen dasar (basic elements) perpustakaan digital yang ideal, karena itu perlu dikaji kondisi obyektif elemen dasar Perpustakaan STP dan membandingkannya dengan kondisi elemen dasar ideal tersebut. Tujuan penelitian ini adalah untuk mengetahui seberapa besar tingkat kelayakan elemen dasar yang dimiliki oleh Perpustakaan STP, mendefinisikan kebutuhan elemen dasar digital yang harus dimiliki dan memformulasikan saran dan rekomendasi kondisi standar elemen dasar perpustakaan digital berbasis web.

Penelitian dilaksanakan di perpustakaan STP Jurluhkan Bogor dan Pustaka Bogor terhadap elemen dasar pengembangan perpustakaan digital berbasis web, yaitu: SDM, koleksi, infrastruktur, SOP, anggaran dan manajemen. Penelitian membahas tingkat kelayakan, memformulasikan dan merekomendasikan kondisi standar elemen dasar perpustakaan digital berbasis web.

\section{METODE PENELITIAN}

\section{Pendekatan}

Pendekatan dilakukan dengan cara menganalisis kondisi standar elemen dasar perpustakaan digital Pustaka Bogor sebagai perpustakaan rujukan dalam penerapan perpustakaan digital dan kondisi membandingkannya (benchmarking) dengan obyektif elemen dasar perpustakaan digital perpustakaan STP Jurluhkan Bogor, kemudian kondisi kondisi ideal elemen dasar perpustakaan digital berbasis web menurut CAUDIT (2001), APJII dan PPAUME (2000), IEEE (2009), NISO (2007), IFLA (2009) dan studi literatur. Dengan cara ini dapat diketahui sejauh mana elemen dasar ideal perpustakaan digital dapat terpenuhi oleh elemen dasar obyektif perpustakaan Pustaka Bogor dan STP Jurluhkan Bogor.

Selanjutnya data yang diperoleh diolah, dianalisis dan digunakan untuk menentukan tingkat kelayakan serta merekomendasikan kondisi standar elemen dasar di perpustakan STP Jurluhkan Bogor.

\section{Kerangka Penelitian}

Pada studi kelayakan ini tahapan pelaksanaan penelitian tersebut dilakukan melalui serangkain proses penelitian sebagaimana pada Gambar $1 \mathrm{di}$ bawah ini.

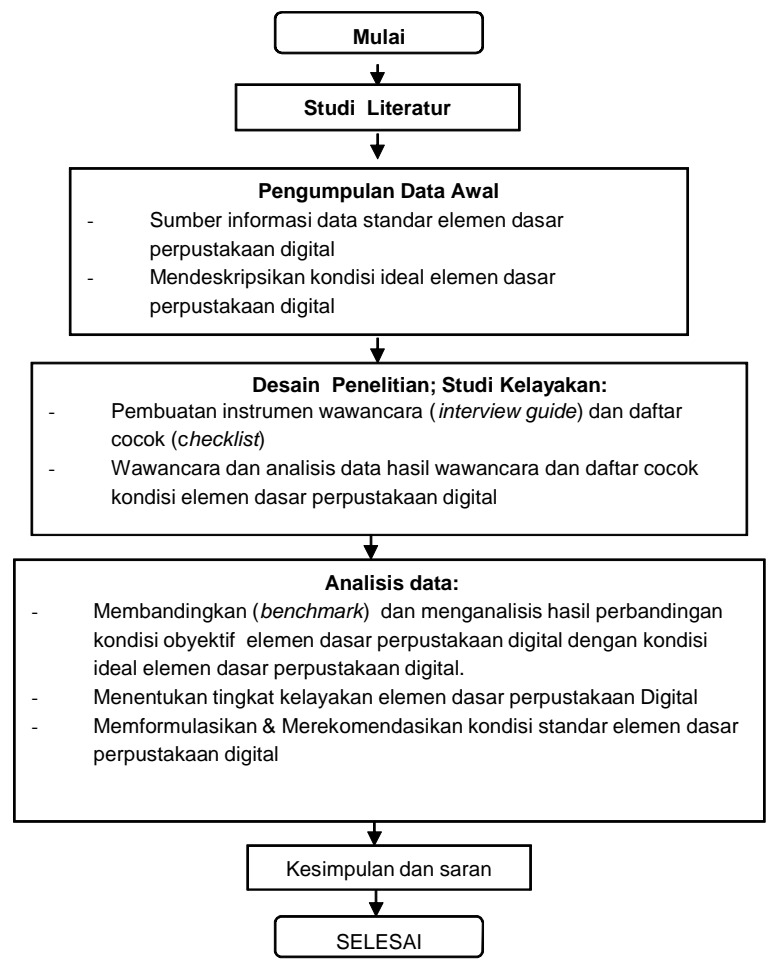

Gambar 1. Langkah-langkah Penelitian 


\section{Prosedur Penelitian}

Berdasarkan langkah-langkah penelitian pada Gambar 1 tersebut, maka tahapan penelitian yang dilakukan adalah sebagai berikut:

\section{A.Studi Literatur}

Untuk mendapatkan pemahaman mengenai standar kondisi ideal elemen dasar perpustakaan digital berbasis web.

\section{B. Pengumpulan Data Awal}

Mengumpulkan data dari berbagai sumber informasi untuk mendeskripsikan kondisi ideal elemen dasar pengembangan sistem perpustakaan digital berbasis web. Sumber-sumber data berupa tempat ( $p$ lece) dari lembaga-lembaga standardisasi antara lain CAUDIT (2001), PPAUME dan APJII (2000), IEEE (2009), NISO (2007) dan IFLA (2009). Sumber data lain berupa simbol (paper) berupa buku, sumber litertur offline dan online serta sumber data berupa orang (person) yaitu para pengelola perpustakaan.

\section{Desain Penelitian}

Menggunakan desain penelitian deskriptif studi kasus (case study) dengan melakukan studi kelayakan, yaitu studi kasus yang bersifat evaluatif yang ditujukan pada layak tidaknya suatu tindakan atau usaha dilakukan.

Masalah yang dianalisis adalah elemen dasar perpustakaan digital berbasis web, yaitu: kelayakan sumber daya manusia, kelayakan koleksi digital, kelayakan infrastruktur, kelayakan standard operational procedure (SOP), kelayakan manajemen dan kelayakan anggaran. Tahapan studi kelayakan yang dilakukan adalah sebagai berikut:

\section{a. Pembuatan instrumen wawancara:}

Instrumen yang dibuat adalah jenis instrument wawancara (interview guide) dan daftar cocok (checklist). Untuk memperoleh data dari setiap variabel, maka instrumen tersebut dibagi terhadap 6 (enam) bagian elemen dasar perpustakaan digi- tal, yaitu: (a) Instrumen untuk data SDM, (b) Instrumen untuk data koleksi, (c) Instrumen untuk data infrastruktur, (d) Instrumen untuk data SOP, (e) Instrumen untuk data manajemen, (f) Instrumen untuk data anggaran.

\section{b. Pengumpulan data:}

Pengumpulan data dengan wawancara (interview guide) dan daftar cocok (checklist) dilakukan kepada pengelola perpustakaan. Selain itu Pengumpulan data dilakukan juga melalui studi kepustakaan dan browsing internet.

\section{c. Analisis data hasil wawancara:}

Analisis data hasil wawancara dilakukan untuk membuktikan dan mengetahui kondisi obyektif tingkat kelayakan kondisi elemen dasar perpustakaan digital Pustaka Bogor dan perpustakaan STP Jurluhkan Bogor.

\section{Analisis Data}

a. Membandingkan (benchmarking) dan menganalisis kondisi obyektif dan kondisi standar terhadap kondisi ideal elemen dasar perpustakaan digital:

b. Menentukan tingkat kelayakan elemen dasar perpustakaan Digital

c. Memformulasikan \& merekomendasikan kondisi standar elemen dasar perpustakaan digital

\section{Tempat dan Waktu Penelitian}

Penelitian akan dilakukan bulan Februari 2011, berlokasi di Pustaka Bogor dan Sekolah Tinggi Perikanan Jurusan Penyuluhan Perikanan Bogor. Pengolahan dan analisis data dilakukan di Laboratorium Pasca Sarjana IImu Komputer-FMIPA, Barangansiang Bogor.

\section{HASIL DAN PEMBAHASAN}

Hasil perbandingan dan analisis hasil kondisi elemen dasar perpustakaan digital STP Jurluhkan Bogor dengan perpustakaan Digital Pustaka Bogor terhadap kondisi ideal elemen dasar perpustakaan digital berbasis web, sebagai berikut: 
Tabel 1. Hasil Perbandingan SDM Perpustakaan Digital antara Pustaka Bogor dengan SDM Perpustakaan Digital STP Jurluhkan Bogor

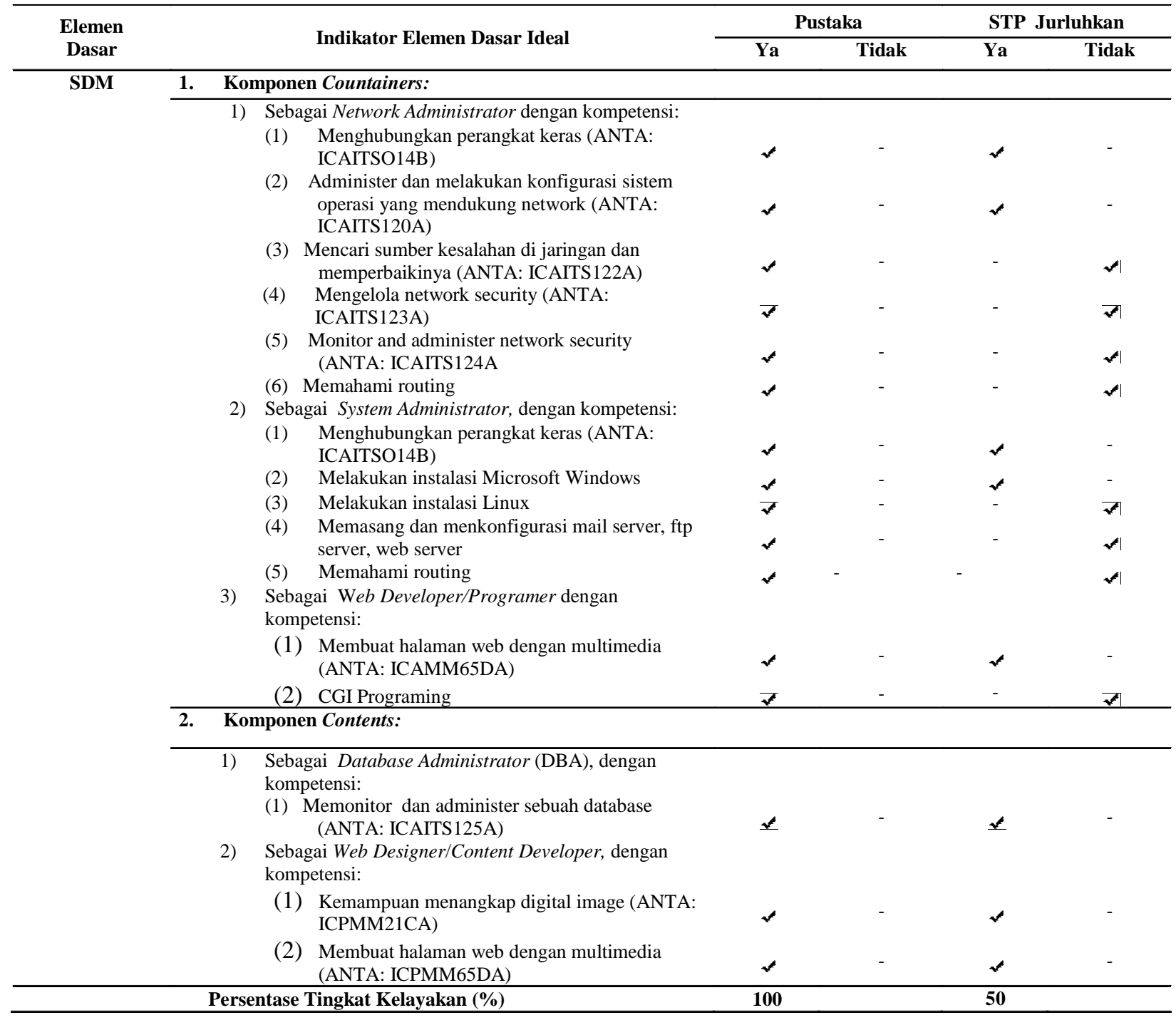

\section{A. Kondisi Sumber Daya Manusia (SDM)}

Analisis elemen dasar SDM dari beberapa indikator sebagaimana Tabel 1 di atas, diperoleh persentase tingkat kelayakan SDM Pustaka Bogor terpenuhi $100 \%$, sedangkan STP Jurluhkan Bogor baru mencapai 50\% meliputi sebagai Network Administrator dengan kompetensi menghubungkan perangkat keras dan melakukan konfigurasi sistem operasional yang mendukung network. Sebagai System Administrator dengan kompetensi menghubungkan perangkat keras dan melakukan instalasi Microsoft Window. Sebagai Web Development Programer dengan kompetensi membuat halaman web dengan multimedia. Sebagai Data Base Administrator (DBA) dengan kompetensi memonitor dan administrator sebuah data base. Sebagai Web Designer/Content
Developer dengan kompetensi kemampuan menangkap digital image dan membuat halaman web dengan multimedia. Hal ini berarti masih diperlukan penyempurnaan untuk mencapai kriteria yang ideal.

\section{B. Kondisi Koleksi Digital}

Analisis elemen dasar koleksi dari beberapa indikator sebagaimana Tabel 2 di bawah, diperoleh persentase tingkat kelayakan koleksi Pustaka Bogor terpenuhi $100 \%$, sedangkan STP Jurluhkan Bogor hanya mencapai $21.4 \%$ yang meliputi indikator karya ilmiah digital, katalog dan video, sedangkan $79.6 \%$ belum terpenuhi. Adapun data hasil perbandingan koleksi Pustaka dengan STP Jurluhkan tertera pada Table 2 . 
Tabel 2. Hasil Perbandingan (Benchmark) Koleksi Perpustakaan Digital Pustaka Bogor dengan Perpustakaan Digital STP Jurluhkan Bogor

\begin{tabular}{|c|c|c|c|c|c|}
\hline \multirow{2}{*}{$\begin{array}{c}\text { Elemen } \\
\text { Dasar Koleksi }\end{array}$} & \multirow{2}{*}{ Indikator Elemen Dasar Ideal } & \multicolumn{2}{|c|}{ Pustaka } & \multicolumn{2}{|c|}{ STP Jurluhkan } \\
\hline & & \multirow[t]{2}{*}{ Ya } & \multirow[t]{2}{*}{ Tidak } & \multirow[t]{2}{*}{$\mathbf{Y a}$} & \multirow[t]{2}{*}{ Tidak } \\
\hline & 1. Bahan dan sumber daya digital fulltext: & & & & \\
\hline & 1) E- journal & $\mid$ & - & - & $\mid$ \\
\hline & 2) E-book & 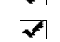 & - & - & $\nabla$ \\
\hline & 3) E-newspaper & $\nabla$ & - & - & $\nabla$ \\
\hline & 4) E-zines & $\nabla$ & - & - & $\nabla$ \\
\hline & 5) Database online & $\square$ & - & - & $\nabla$ \\
\hline & 6) Karya ilmiah digital & $\nabla$ & - & $\nabla$ & - \\
\hline \multicolumn{6}{|c|}{ 1. Sumberdaya metada: } \\
\hline & 1) Katalog & 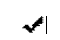 & - & $\nabla$ & - \\
\hline & 2) Indeks & $\mid$ & - & - & $\mid$ \\
\hline & 3) Abstrak & $|\neg|$ & - & - & $\mid$ \\
\hline \multicolumn{6}{|c|}{ 2. Bahan-bahan multimedia digital: } \\
\hline & 1) Images & $\nabla$ & - & - & $\nabla$ \\
\hline & 2) Animation & $|\sim|$ & - & - & $\mid$ \\
\hline & 3) Video & 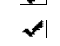 & - & 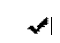 & - \\
\hline & 4) Audio & 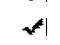 & - & - & $\nabla$ \\
\hline \multicolumn{2}{|r|}{ 3. Aneka situs di internet } & $\nabla$ & - & - & $\nabla$ \\
\hline \multicolumn{2}{|r|}{ Persentase Tingkat Kelayakan } & 100 & & 21,4 & \\
\hline
\end{tabular}

\section{Kondisi Infrastruktur}

Analisis elemen dasar terkait dengan infrastruktur dari beberapa indikator sebagaimana Tabel 3 di bawah, diperoleh persentase tingkat kelayakan infrastruktur Pustaka Bogor terpenuhi 100\%, dan STP Jurluhkan Bogor diperoleh prosentase tingkat kelayakan $95,3 \%$, yang berarti bahwa hampir semua indikator elemen dasar ideal sudah terpenuhi, kecuali computer server.

Tabel 3. Hasil Perbandingan Infrastruktur Perpustakaan Digital Pustaka Bogor denganPerpustakaan Digital STP Jurluhkan Bogor

\begin{tabular}{|c|c|c|c|c|c|c|}
\hline \multirow{2}{*}{$\begin{array}{c}\text { Elemen } \\
\text { Dasar }\end{array}$} & \multirow{2}{*}{\multicolumn{2}{|c|}{ Indikator Elemen Dasar Ideal }} & \multicolumn{2}{|c|}{ Pustaka } & \multicolumn{2}{|c|}{ STP Jurluhkan } \\
\hline & & & $\mathrm{Ya}$ & Tidak & $\mathrm{Ya}$ & Tidak \\
\hline \multirow[t]{25}{*}{ Infrastruktur } & \multirow[t]{13}{*}{1.} & pponen perangkat keras (hardware) minimal: & & & & \\
\hline & & 1 set computer server & 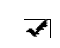 & - & - & $\bar{z}$ \\
\hline & & 4 set personal computer & $\checkmark$ & - & $\nabla$ & - \\
\hline & & 1 unit $h u b$ & $\nabla$ & - & $\nabla$ & - \\
\hline & & 1 unit router & 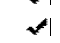 & - & 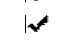 & - \\
\hline & & 1 buah modem & 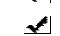 & - & $\mid$ & - \\
\hline & & 1 unit $U P S$ & $\$$ & - & 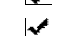 & - \\
\hline & & 1 set kabel konektor & 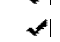 & - & $\nabla$ & - \\
\hline & & 1 set instalasi listrik & 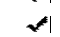 & - & $\mid$ & - \\
\hline & & 1 set instalasi jaringan & 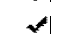 & - & $\nabla$ & - \\
\hline & & 1 unit saluran telpon & $\checkmark$ & - & 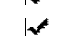 & - \\
\hline & & 1 unit printer & 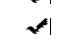 & - & $\nabla$ & - \\
\hline & & 1 unit scanner & $\nabla$ & - & $\nabla$ & - \\
\hline & \multicolumn{6}{|c|}{ 2. Komponen perangkat lunak: } \\
\hline & 1) & Operating system & $\nabla$ & - & $\nabla$ & - \\
\hline & 2) & Database management system & 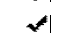 & - & 正 & - \\
\hline & 3) & Web browser & 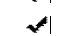 & - & $\nabla$ & - \\
\hline & 4) & Aplikasi interface & $\neg$ & - & $\nabla$ & - \\
\hline & 5) & Web server & 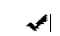 & - & $ه$ & - \\
\hline & 6) & Bahasa pemrograman & ح & - & 田 & - \\
\hline & \multicolumn{6}{|c|}{ 3. Jaringan: } \\
\hline & 1) & Local Area Network & $\checkmark$ & - & $\mid$ & - \\
\hline & 2) & Internet & t & - & 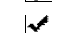 & - \\
\hline & 3) & Website & 2 & - & $\mid$ & - \\
\hline & \multicolumn{2}{|c|}{ Persentase Tingkat Kelayakan } & 100 & & 95,2 & \\
\hline
\end{tabular}

\section{Kondisi SOP}

Analisis elemen dasar infrastruktur dari beberapa indikator sebagaimana Tabel 4 di bawah, diperoleh persentase tingkat kelayakan SOP Pustaka Bogor terpenuhi $100 \%$, sedangkan STP Jurluhkan masih 0
$\%$. Hal ini berarti semua Standard Operation Procedure $(S O P)$ yang meliputi konversi dokumen, upload ke web, pengolahan dokumen digital, sistem pelayanan pustakaan digital, pemeliharaan jarigan dan pemeliharaan web semuanya belum dimiliki oleh STP Jurluhkan Bogor, sehingga perlu dilengkapi. 
Tabel 4. Hasil Perbandingan SOP Perpustakaan Digital Pustaka Bogor dengan Perpustakaan Digital STP Jurluhkan Bogor

\begin{tabular}{|c|c|c|c|c|c|}
\hline \multirow{3}{*}{$\begin{array}{c}\begin{array}{c}\text { Elemen } \\
\text { Dasar }\end{array} \\
\text { SOP }\end{array}$} & \multirow{2}{*}{ Indikator Elemen Dasar Ideal } & \multicolumn{2}{|c|}{ Pustaka } & \multirow{2}{*}{\multicolumn{2}{|c|}{$\begin{array}{cc}\text { STP } & \text { Jurluhkan } \\
\text { Ya } & \text { Tidak }\end{array}$}} \\
\hline & & $\mathbf{Y a}$ & Tidak & & \\
\hline & Perpustakaan memiliki: & & & & \\
\hline & 1) SOP konversi dokumen. & w & - & - & |مها \\
\hline & 2) SOP upload ke web. & 12 & - & - & $\mid$ \\
\hline & 3) $S O P$ pengolahan dokumen digital. & 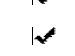 & - & - & |ها \\
\hline & 4) $S O P$ sistem layanan perpust. digital. & 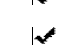 & - & - & 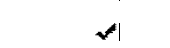 \\
\hline & 5) $S O P$ pemeliharaan jaringan . & 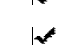 & - & - & 番 \\
\hline & 6) SOP pemeliharaan web. & 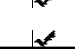 & - & - & 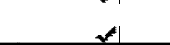 \\
\hline & Persentase Tingkat Kelayakan & 100 & & $\mathbf{0}$ & \\
\hline
\end{tabular}

\section{E. Kondisi Manajeman}

Analisis elemen dasar manajemen dari beberapa indikator sebagaimana Tabel 5 di bawah, diperoleh persentase tingkat kelayakan manajemen Pustaka Bogor terpenuhi 100\%, sedangkan STP Jurluhkan baru mencapai $58,3 \%$. Hal ini berarti yang sudah terpenuhi elemen scanning, editing, uploading, penyipanan, pendistribusian, pelestarian, sedangkan $41,7 \%$ belum terpenuh oleh STP Jurluhkan, sehingga perlu dilengkapi. Adapun grafik tingkat kelayakan manajemen tertera pada Gambar 6 .

\section{F. Kondisi Anggaran}

Analisis elemen dasar anggaran dari beberapa indikator sebagaimana Tabel 6 di bawah, diperoleh persentase tingkat kelayakan koleksi Pustaka Bogor terpenuhi $100 \%$, sedangkan STP Jurluhkan hanya mencapai 33,33 \%. Hal ini berarti hanyaanggaran perangkat keras, perangkat lunak dan perangkat jaringan yang sudah dimiliki STP Jurluhkan Bogor, sehingga elemen dasar lain sebanyak $66,67 \%$ perlu dilengkapi.

Tabel 5. Hasil Perbandingan Manajemen Perpustakaan Digital Pustaka Bogor dengan Perpustakaan Digital STP Jurluhkan Bogor

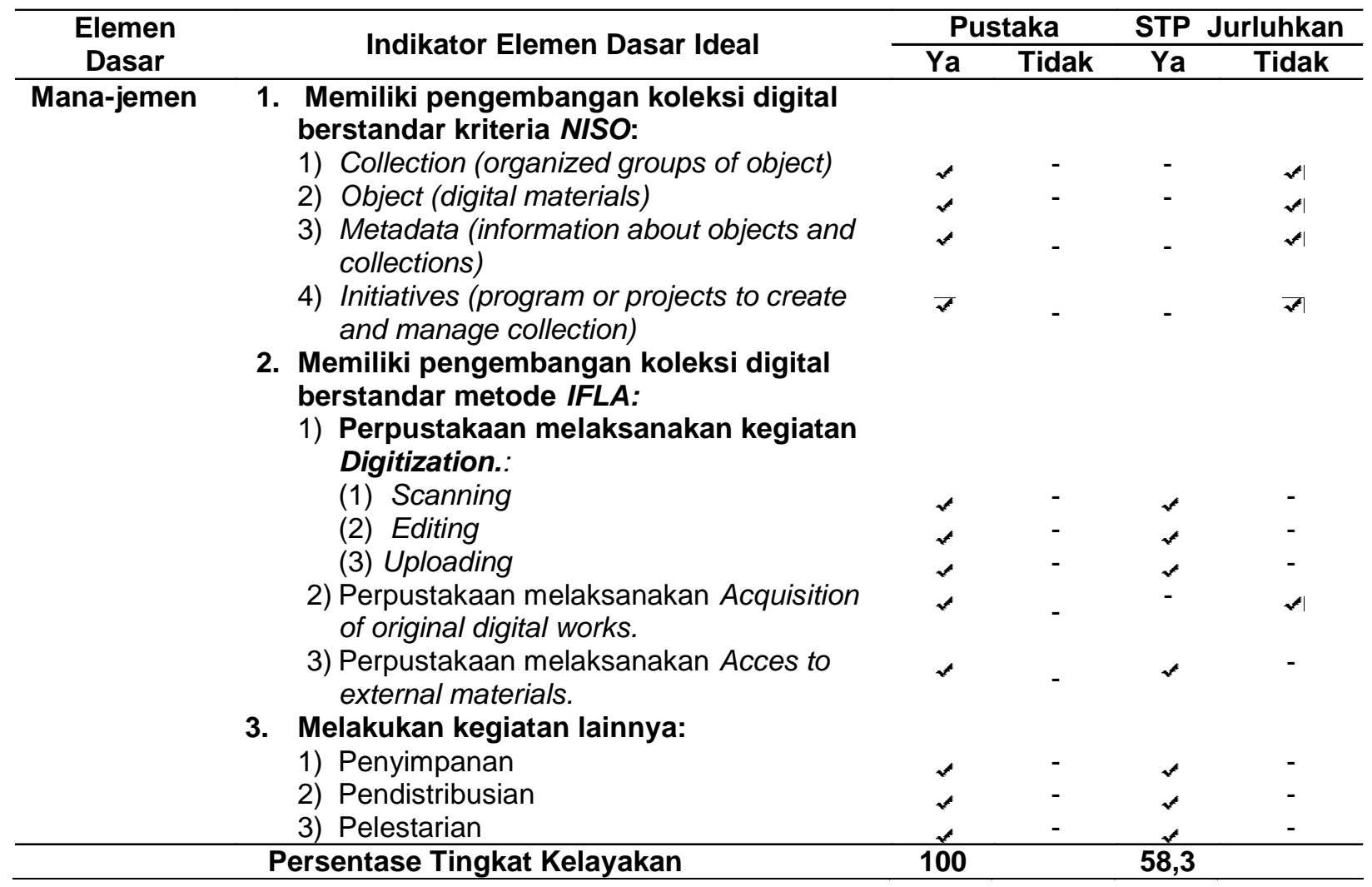


Tabel 6 Hasil Perbandingan Anggaran Perpustakaan Digital Pustaka Bogor dengan Perpustakaan Digital STP Jurluhkan Bogor

\begin{tabular}{|c|c|c|c|c|c|}
\hline \multirow{2}{*}{$\begin{array}{c}\text { Elemen } \\
\text { Dasar }\end{array}$} & \multirow{2}{*}{ Indikator Elemen Dasar Ideal } & \multicolumn{2}{|c|}{ Pustaka } & \multicolumn{2}{|c|}{ STP Jurluhkan } \\
\hline & & $\mathrm{Ya}$ & Tidak & $\mathrm{Ya}$ & Tidak \\
\hline \multirow[t]{12}{*}{ Anggaran } & 1. Pendanaan investasi, yaitu: & & & & \\
\hline & 1) Perangkat keras & $\nabla$ & - & $\nabla$ & - \\
\hline & 2) Perangkat lunak & $\nabla$ & - & $\nabla$ & - \\
\hline & 3) Perangkat jaringan & 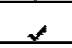 & - & $\mid$ & - \\
\hline & 2. Pendanaan operasional : & & & & \\
\hline & 1) Digitalisasi. & $\nabla$ & - & - & $\nabla$ \\
\hline & 2) Acquisition of original digital works. & 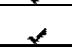 & - & - & 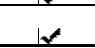 \\
\hline & 3) Acces to external materials. & $\nabla$ & - & - & $\nabla$ \\
\hline & 4) Penyimpanan & 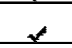 & - & - & 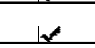 \\
\hline & 5) Pendistribusian & 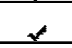 & - & - & $\mid$ \\
\hline & 6) Pelestarian & 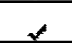 & - & - & 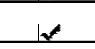 \\
\hline & Persentase Tingkat Kelayakan & 100 & & 33,33 & \\
\hline
\end{tabular}

\section{G. Rekapitulasi k Kondisi Elemen Dasar}

Hasil rekapitulasi perbandingan tingkat kelayakan elemen dasar perpustakaan digital Pustaka Bogor dan perpustakaan digital STP Jurluhkan Bogor terhadap kondisi ideal elemen dasar tercantum dalam Tabel 7 dibawah ini:

Berdasarkan analisis hasil wawancara, perbandingan dan rekapitulasi hasil perbandingan tersebut di atas menunjukan bahwa semua kondisi ideal elemen dasar perpustakaan digital terpenuhi 100 $\%$ oleh perpustakaan Pustaka Bogor yang membuktikan bahwa kondisi elemen dasar sudah layak dalam mengembangkan perpustakaan digital berbasis web. Sedangkan di Perpustakaan STP Jurluhkan menunjukan bahwa semua kondisi ideal elemen dasar perpustakaan digital belum terpenuhi $100 \%$ yang menunjukan bahwa kondisi elemen dasar perpustakaan STP Jurluhkan Bogor belum layak dalam mengembangankan perpustakaan digital berbasis web.

Tabel 7 Hasil Rekapitulasi Perbandingan Tingkat Kelayakan Elemen Dasar Pustaka Bogor dan Perpustakaan Digital STP Jurluhkan Bogor Terhadap Indikator Elemen Dasar Ideal Perpustakaan Digital berbasis Web

\begin{tabular}{clcc}
\hline \multirow{2}{*}{ No. } & & \multirow{2}{*}{ Elemen Dasar } & \multicolumn{2}{c}{ Tingkat Kelayakan (\%) } \\
\cline { 3 - 4 } & & 100 & Pustaka \\
\hline 1 & Sumber Daya Manusia & 100 & 50,00 \\
2 & Koleksi & 100 & 21,40 \\
3 & Infrastruktur & 100 & 95,20 \\
4 & SOP & 100 & 0,00 \\
5 & Manajemen & 100 & 58,30 \\
6 & Anggaran & & 33,33 \\
\hline
\end{tabular}

H. Rekomendasi Untuk Perpustakaan Digital Berbasis Web bagi STP Jurluhkan Bogor

Berdasarkan hasil analisis data, maka penulis merekomendasikan beberapa kriteria dan kondisi, sehingga STP Jurluhkan Bogor memenuhi tingkat kelayakan sampai $100 \%$. Adapun rekomendasi yang diusulkan berdasarkan enam elemen dasar ideal seperti tertera pada tabel 8 . 
Tabel 8. Rekomendasi Indikator Elemen Dasar Pengembangan Perpustakaan Berbasis Web

\begin{tabular}{|c|c|c|c|c|}
\hline No & Elemen Dasar & Rekomendasi & Solusi & Teknis Pelaksanaan \\
\hline 1. & SDM & $\begin{array}{l}\text { Agar secara bertahap } \\
\text { diupayakan } \\
\text { peningkatan tingkat } \\
\text { kelayakan SDM yang } \\
\text { ada }\end{array}$ & $\begin{array}{l}\text { Menambah SDM yang } \\
\text { kompeten di bidang IT sesuai } \\
\text { standar,yaitu: } \\
\text { 1. Network administrator } \\
\text { 2. System administrator } \\
\text { 3. Web developer } \\
\text { 4. Darabase adminisrator } \\
\text { 5. Web designer }\end{array}$ & $\begin{array}{l}\text { 1. Rekruitmen SDM dengan } \\
\text { pengangkatan CPNS } \\
\text { 2. Mutasi dengan prinsip:the } \\
\text { right man in the rigtht } \\
\text { place, melalui: } \\
\text { 1) Program Pendidikan } \\
\text { 2) Pelatihan dan } \\
\text { Magang } \\
\text { 3. Alih fungsi, melalui: } \\
\text { 1) Program Pendidikan } \\
\text { 2) Pelatihan dan } \\
\text { Magang }\end{array}$ \\
\hline 2. & Koleksi & $\begin{array}{l}\text { Agar secara bertahap } \\
\text { diupayakan } \\
\text { peningkatan tingkat } \\
\text { kelayakan koleksi yang } \\
\text { ada. }\end{array}$ & $\begin{array}{l}\text { Melengkapi dan menambah } \\
\text { koleksi pustaka digital yang } \\
\text { berkualitas: } \\
\text { 1. Fulltext } \\
\text { 2. Sumberdaya metadata } \\
\text { 3. Bahan-bahan multimedia } \\
\text { digital } \\
\text { 4. Menghimpun aneka situs } \\
\text { dari Internet }\end{array}$ & $\begin{array}{ll}\text { 1. Melaksanakan digitalisasi } \\
\text { 2. Melaksanakan Konversi } \\
\text { 3. Melaksakan Burning } \\
\text { 4. Mengajukan pembelian } \\
\text { 5. Mengajukan } \\
\text { berlangganan. } \\
\text { 6. Download koleksi digital } \\
\text { open source. } \\
\text { 7. Bekerjasama dengan } \\
\text { perpustakaan- } \\
\text { perpustakaan digital. }\end{array}$ \\
\hline 3. & Infrastruktur & $\begin{array}{l}\text { Agar secara bertahap } \\
\text { diupayakan } \\
\text { peningkatan tingkat } \\
\text { kelayakan Infrastruktur } \\
\text { yang ada. }\end{array}$ & $\begin{array}{l}\text { Melengkapi dan meningkatkan } \\
\text { kapasitas Infrastruktur: } \\
\text { 1. Hardware }(\mathrm{HW}) \\
\text { 2. Software }(\mathrm{SW}) \\
\text { 3. Netware (NW) }\end{array}$ & $\begin{array}{l}\text { Melakukan up grade } \\
\text { secara berkala. }\end{array}$ \\
\hline 4. & SOP & $\begin{array}{l}\text { Agar secara bertahap } \\
\text { diupayakan } \\
\text { peningkatan tingkat } \\
\text { kelayakan SOP yang } \\
\text { ada. }\end{array}$ & Menyusun SOP & $\begin{array}{l}\text { Tahapan penyusunan SOP, } \\
\text { yaitu: } \\
\text { 1. Analisis kebutuhan SOP, } \\
\text { 2. Pengembangan SOP, } \\
\text { 3. Penerapan SOP, } \\
\text { 4. Monitoring dan evaluasi. }\end{array}$ \\
\hline 5. & Manajemen & $\begin{array}{l}\text { Agar secara bertahap } \\
\text { diupayakan } \\
\text { peningkatan tingkat } \\
\text { kelayakan SDM yang } \\
\text { ada. }\end{array}$ & $\begin{array}{l}\text { 1. Melakukan pengembangan } \\
\text { koleksi berstandar kriteria } \\
\text { NISO } \\
\text { 2. Melakukan pengembangan } \\
\text { koleksi berstandar metode } \\
\text { IFLA, yaitu: Acquisition of } \\
\text { original digital work }\end{array}$ & $\begin{array}{l}\text { 1. Menyusun perencanaan } \\
\text { berstandar NISO dan } \\
\text { metode IFLA serta SOP. } \\
\text { 2. Menyusun perencanaan } \\
\text { dengan memperhatikan } \\
\text { kondisi elemen dasar } \\
\text { lainnya. }\end{array}$ \\
\hline 6. & Anggaran & $\begin{array}{l}\text { Agar secara bertahap } \\
\text { diupayakan } \\
\text { peningkatan tingkat } \\
\text { kelayakan anggaran } \\
\text { yang ada. }\end{array}$ & $\begin{array}{l}\text { Agar menyusun dan } \\
\text { mengajukan anggaran: } \\
\text { 1. Investasi } \\
\text { 2. Operasional } \\
\text { 3. Kegiatan lainnya }\end{array}$ & $\begin{array}{l}\text { Agar menyusun dan } \\
\text { mengajukan anggaran: } \\
\text { 1. Investasi } \\
\text { 2. Operasional } \\
\text { 3. Kegiatan lainnya }\end{array}$ \\
\hline
\end{tabular}

\section{KESIMPULAN DAN SARAN}

\section{Kesimpulan}

a Berdasarkan data dari hasil dan pembahasan diperoleh kondisi tingkat kelayakan elemen dasar perpustakaan digital berbasis web perpustakaan Pustaka Bogor mencapai $100 \%$. Kondisi tingkat kelayakan tersebut membuktikan bahwa kondisi elemen dasar perpustakaan Pustaka Bogor sudah layak dalam mengembangkan perpustakaan digital berbasis web. b Berdasarkan data dari hasil dan pembahasan diperoleh kondisi tingkat kelayakan elemen dasar perpustakaan digital berbasis web perpustakaan STP jurluhkan Bogor yaitu $50.00 \%$ kondisi elemen dasar SDM, 21,40\% kondisi elemen dasar koleksi, $95,20 \%$ kondisi elemen dasar infrastruktur, 0.00 $\%$, kondisi elemen dasar SOP dan $58,30 \%$ kondisi elemen dasar manajemen serta $33.33 \%$ kondisi elemen dasar Anggaran. 
c Berdasarkan tingkat kelayakan tersebut perpustakaan STP Jurluhkan Bogor belum layak untuk melakukan pengembangan perpustakaan digital berbasis web.

d Perpustakaan STP Jurluhkan Bogor perlu meningkatkan kelayakan elemen dasar perpustakaan digitalnya agar dapat mengembangkan perpustakaan digital berbasis web-nya.

\section{Saran}

a. Kondisi elemen dasar ideal agar segera dipenuhi dan kembangkan, sehingga semua persyaratan tingkat kelayakan perpustakaan digital berbasis web bagi STP Jurluhkan Bogor dapat terwujud dengan layak dan optimal.

b. Dalam upaya untuk melengkapi semua elemen ideal termaksud serta proses pengembangannya, maka sebaiknya dapat dilakukan dengan berpedoman kepada rekomdasi hasil penelitian ini.

c. Penelitian ini dapat dilanjutkan lebih mendalam dengan melakukan antara lain berupa analisis terhadap masing-masing komponen elemen dasar pengembangan perpustakaan digital berbasis ueb

\section{Daftar Pustaka}

[CAUDIT] Council of Australian University Directors of Information Teknology (2001) Common IT Posi- tion Descriptions Project. [WWW] .Australia: Del Cseti Associates, pp. 34-36 [18/08/10]

[IEEE] Institute of Electrical and Electronics Engineers (2001) Standarisasi IEEE, ANSI, TIA, EIA Tersedia dari:http://blog.unsri.ac.id/aswin/jaringankomputer/standarisasi-ieee-ansi-tia-eia-dkk/ mrdetail/341/

[NISO] National Information Standards Organizatio, 2007. A Framework of Guidance for Building Good Digital Cillections. $3^{\text {rd }}$ Edition. Baltimore: NISO with supportfrom the Institut of Museum and Library Services.

Rufaidah VW. 2007. Knowledge Commerce: Peluang Implementasinya di Pusat Perpustakaan dan Penyebaran Teknologi Pertanian. Jurnal Perpustakaan Pertanian. Vol. 16. No. 2, 2007 hal. 44-50

Sastraatmadja T. (2003) Konsep Peningkatan Daya Saing Pada Pelayanan Jasa Informasi, di Perpustakaan.[WWW] Tersedia dari: http:// www.google.com/search?hl= \&q=Pengukuhan +pustakawan+utama+Tintin+S+\&sourceid=navclientff \&rlz=1B3WZPB_enID 351ID353\&ie=UTF-8 [20/ 08/10] 
J.Pari Vol. 4 No. 2 Desember 2018 : 